\title{
UNA APROXIMACIÓN A LA TEORIA HERMENÉUTICA DE LA IMAGINACIÓN DE PAUL RICEUR: DE LA METÁFORA AL IMAGINARIO SOCIAL
}

\author{
A. Federico Adaya Leite \\ Universidad Autónoma del Estado de México
}

\section{Introducción}

El trabajo que a continuación se expone tiene el objetivo de realizar una aproximación a la teoría de la imaginación en Paul Riccur. Dicho problema es una constante en su filosofia y es un elemento constitutivo de la antropología filosófica que construye a lo largo su reflexión. Se encuentra en la descripción fenomenológica del actuar humano, ' y en el análisis de inspiración kantiana sobre la labilidad humana o desproporción ontológica. ${ }^{2}$ También se aborda en el estudio sobre la metáfora ${ }^{3}$ y en la noción de identidad narrativa que trata en la trilogía de Temps et Récit. Por otra parte, se haya de forma implícita en La symbolique du mal y De l'intérpretation. Essais sur Freud. Finalmente aparece en la fenomenología de hombre capaz, que desarrolla tanto en Soi-même comme un autre, como en su última obra Parcours de la reconnaissance. ${ }^{5}$

1 Cf. Paul Ricœur, Philosophie de la volonté L, Le volontaire et l'involontaire, Paris, Aubier, 1950, pp. 82-116.

${ }^{2}$ Cf. Paul Ricœur, Philosophie de la volonté 2. Finitude et culpabilité, L'homme faillible, Paris, Aubier, 1960, pp. 122-124, 127-162.

3 Cf. Paul Riccur, La Métaphore vive, Paris, Seuil, 1997 (Col. Points Essais, n 347), pp. 238-242, 245-272, 374-399.

4 Cf. Paul Ricœur, Philosophie de la velonté 2, Finitude et culpabilité, La symbolique du mal, Paris, Aubier, 1960, pp. 17-25. En esta parte, Ricœur desarrolla la criteriología del símbolo en sus tres dimensiones: cósmica, onírica y poética. Toda la obra supone el concepto de imaginación creativa.

5 Cf. Paul Ricœur, Parcours de la reconnaissance, Paris, Gallimard, 2005 (Col. Folio Essais, no. 459), pp. 149 - 178, 341 - 378. Una fenomenología del hombre capaz supone la imaginación, debido a que ella se encuentra tanto como un elemento constitutivo del "poder hacer", como en el concepto husserliano de percepción analógica por el cual Ricœur aborda el problema del reconocimiento. 
Ya que no es posible analizar todos estos momentos en el presente artículo, sólo se tomarán tres aspectos en los que se plantea el tema de la imaginación: la metáfora, el mundo del texto, y el imaginario social y cultural. La elección de éstos, permitirá por una parte identificar los conceptos que articulan la noción de imaginación, por otra, se verá la trascendencia de este problema en el conjunto de la propuesta del pensador francés. Por último se mostrará que la fenomenología hermenéutica que elabora Ricœur no se limita a ser una metodología de la interpretación textual, sino que también es una reflexión crítica que permite la comprensión de la realidad social.

\section{La imaginación en la metáfora}

A continuación se presentarán algunos rasgos básicos de la metáfora, que Ricœur investiga en su obra Métaphore vive para después exponer la naturaleza y la función que la imaginación desempeña en ella.

En primer lugar y en sentido estricto de lo que hay que hablar es de enunciado metafórico. La metáfora considerada desde el punto de vista semántico se entiende no como la desviación del significado de la palabra, sino como la interacción entre diversos campos semánticos que en su sentido literal no tienen ninguna relación. Utilizando el lenguaje de Max Black se puede afirmar que la metáfora es un enunciado en el que se da un contraste entre una palabra (foco) y el resto del enunciado (marco). ${ }^{6}$ Desde esta perspectiva, la unidad básica de significación no recae en la palabra, sino en el enunciado entero. La segunda característica del enunciado metafórico es la semejanza, la cual consiste en la acción de acercar, de hacer familiar, lo que aparece lejano y extraño. De esta forma, la impertinencia semántica que se da a nivel de lenguaje ordinario entre el foco y el marco, se supera para crear una nueva significación. ${ }^{7}$ La tercera característica es la dimensión ontológica o referencia con la realidad. Ricœur utiliza el término de "referencia desdoblada" para explicar este rasgo. La referencia desdoblada, consiste en que la metáfora realiza una epojé sobre la significación del lenguaje ordinario para liberar un sentido segundo que permite captar de manera distinta la realidad. Esta manera no-ordinaria de percibir y de relacionarse con la realidad, pone de manifiesto una manera prejudicativa de ser y estar en el mundo. El siguiente rasgo esencial viene a ser el corolario de las características anteriores: la verdad. La verdad del enunciado metafórico encuentra su lugar principalmente en el verbo, que mantiene y condensa las contradicciones anteriormente descritas: tensión entre el foco y el marco, tensión entre el sentido literal y el sentido poético de la referencia desdoblada. En el verbo metafórico la tensión se expresa al afirmar que algo 
es y no es. En la metáfora "la naturaleza es un templo de pilares vivientes", las tensiones anteriores se condensan en el verbo, que en su sentido literal dice algo que no es: la naturaleza no es un templo. Pero en su sentido poético, la naturaleza es transformada en un templo. El verbo metafórico tiene una estructura tensional que le permite afirmar que algo es y no es y que se manifiesta en la expresión "ser-como". 8

A partir de algunas características esenciales de la metáfora se analizará la naturaleza y función de la imaginación en la metáfora.

Ricœur relaciona la imaginación con la primera característica de la metáfora mencionada anteriormente, y sostiene que: "La imaginación es la apercepción, es la vista repentina de una nueva pertinencia predicativa... Imaginar es reestructurar los campos semánticos". ${ }^{9}$ Como se puede observar a partir de la contradicción o tensión entre campos semánticos (o también se puede decir entre el foco y el marco) se realiza una impertinencia semántica que se expresa en la búsqueda de lo semejante en lo diferente, posibilitando que algo se "vea como". En esta aproximación participa la imaginación que es la capacidad intuitiva para realizar este acercamiento. Esta primera característica se profundiza cuando se le considera desde la noción del esquematismo kantiano. ${ }^{10}$ Desde esta perspectiva, la imaginación es tanto un método para que un concepto tenga una imagen, como una regla para producir imágenes. ${ }^{11} \mathrm{La}$ imaginación, por tanto, además de ser la captación intuitiva de lo semejante, es una operación que posibilita dicha semejanza. La imaginación es la matriz que funda la innovación semántica, y en última instancia la condición de posibilidad del "ver como".

Pero el papel que desempeña la imaginación creativa en la metáfora no termina aquí. En este nivel de nuestra reflexión se puede preguntar ¿Por qué la metáfora es "viva"? En primer lugar es viva porque a partir de una impertinencia semántica a nivel del lenguaje ordinario, es capaz de crear una innovación semántica a nivel del lenguaje poético. Es un "error calculado" en palabras de Gilbert Ryle. ${ }^{12}$ En segundo lugar, el enunciado metafórico tiene la capacidad de revelar las posibilidades más propias del ser humano y de la misma realidad, al ser recreados por el lenguaje. ${ }^{13}$ Por este proceso de recreación, ambos son presentados en su dimensión actuante y concreta.

8 Cf. Ibidem p. 312.

9 Paul Ricœur, Du texte a l'action : Essais d'herméneutique II, Paris, Seuil, 1998 (Col. Points Essais, no. 377), p. 243.

10 Cf. Marie-France Begué, Paul Ricœur: La poética del sí-mismo, Buenos Aires, Biblos, 2002, pp. 33-34. El esquematismo es la base del concepto de imaginación en Kant. Para Kant la imaginación es la facultad que tiene la capacidad de sintetizar lo diverso. En este sentido la imaginación trascendental o imaginación productora, es la que realiza la síntesis entre fenómeno y entendimiento.

11 Cf. Paul Ricœur, op. cit., p. 243.

12 Cf. Paul Ricœur, La Métaphore vive, p. 316.

${ }^{13}$ Cf. Ibidem, p. 289. 
Y por último, la metáfora es viva porque ofrece a la reflexión filosófica una multiplicidad de significaciones que le sirven como punto de partida para la elaboración del concepto. $\mathrm{Y}$ en estas tres dimensiones vitales la imaginación se encuentra presente. Ricœur al referirse a este último aspecto afirma:

La metáfora no es viva sólo en cuanto que ella vivifica un lenguaje constituido. La metáfora es viva también en cuanto que inscribe el impulso de la imaginación en un 'pensar más' a nivel de concepto. Es esta lucha por el 'pensar mas', bajo la dirección del 'principio vivificante', la que es el 'alma' de la interpretación. $^{14}$

\section{La imaginación en el texto}

El paso de la metáfora al texto está asegurado por la dimensión semántica de la metáfora. El enunciado, además de ser un rasgo esencial de la metáfora, constituye la unidad básica de sentido a partir de la cual se construye un texto. En este apartado se presentarán algunos de los rasgos más importantes del texto para luego analizar como la imaginación se manifiesta en esta estructura narrativa de mayor complejidad.

Ricœur considera que el texto es un discurso escrito. ${ }^{15}$ El discurso a su vez se entiende como "el acontecimiento del lenguaje". El término acontecimiento significa que el lenguaje, es decir, el sistema de signos que constituyen un código, es realizado temporalmente en el presente. ${ }^{16}$ Esta realización adquiere una concretización especial pues en el discurso "alguien dice algo a alguien sobre algo según reglas". ${ }^{17}$ Por último, el discurso actualiza el lenguaje, ya que posee una "intencionalidad significante" que se manifiesta al ser comunicado.

Ricœur, a partir de esta noción, distingue entre discurso oral y discurso escrito o texto. El discurso oral se caracteriza porque se lleva a cabo en el tiempo presente y en consecuencia la actualización del lenguaje se encuentra en un constante devenir. Por su parte, el discurso escrito posee un carácter permanente al estar fijado. Otra diferencia radica en que en el discurso oral, el locutor e interlocutor mantienen una relación inmediata que permite explicitar aquello que el primero dice al segundo. En el discurso escrito desaparecen tanto la relación entre el autor y los destinatarios originales, como el contexto

${ }^{14}$ Paul Ricœur, Du texte à l'action : Essais d'herméneutique II, p. 384.

15 Cf. Ibidem, p. 154.

${ }^{16}$ Cf. Ibidem, p. 116.

17 Paul Ricœur, Autobiografia intelectual, Buenos Aires, Nueva Visión, 1997 (Col. Diagonal), p. 14. 
primero en el que se gestó. El texto adquiere una triple autonomía. ${ }^{18} \mathrm{La}$ intención del autor da paso a la significación propia del texto y los destinatarios originales son sustituidos por un público potencialmente abierto. Respecto al contexto original, el texto se encontrará en nuevas situaciones socioculturales que lo abrirán a perspectivas diversas de comprensión. Como se puede apreciar la autonomía del texto exige un ejercicio de interpretación que permita comprender el horizonte de sentido que despliega el texto. ${ }^{19}$

Ahora bien junto a los rasgos de permanencia y autonomía, existen otros que permiten enriquecer la noción de texto. ${ }^{20}$ Cuando el discurso escrito se constituye como obra, se caracteriza además por ser una totalidad finita con un sentido completo y con una estructura lingüística definida. Por otra parte se ordena de acuerdo a ciertas formas de codificación que se denominan géneros literarios. Y por último posee una configuración única que la asemeja a un individuo y que recibe el nombre de estilo. ${ }^{21}$

A partir de estos rasgos esenciales se puede apreciar el rol de la imaginación en un concepto central para el pensamiento del filósofo francés: "el mundo del texto". ${ }^{22}$ Ricœur lo formula a partir de tres nociones básicas: La autonomía del texto, el sentido y la referencia según Frege y la disposición afectiva (Befinlichkeit) y la comprensión (Verstehen), como maneras originarias de ser del Dasein, según la analítica existenciaria de Heidegger. ${ }^{23}$ La primera continúa la noción fenomenológica desarrollada por Gadamer, de "la cosa del texto". ${ }^{24}$ Como se sabe lo que importa en una perspectiva fenomenológica es "ir a las cosas mismas", y en el caso de la hermenéutica, "la cosa misma" es el texto. A diferencia de la hermenéutica romántica que buscaba conocer la intención del autor a través del texto, en la hermenéutica tanto de Ricœur como la de Gadamer la centralidad la ocupa el texto del que proviene el sentido. Por su parte, las nociones de sentido y referencia complementan y agregan un aspecto más al anterior. El sentido es la significación ideal que posee el enunciado. Esta significación se puede mantener a pesar de la variación de los códigos del lenguaje que se utilizan para expresarla. La referencia

18 Cf. Oliver Mongin, Paul Riccur, Paris, Seuil, 1994. p. 137-141. El autor expone de manera general las implicaciones de la triple autonomía del texto en la obra de Ricœur.

19 Cf. Paul Ricœur, Du texte a l'action. Essais d'herméneutique II, pp.155-159.

20 Ricœur propone otros cuatro rasgos que constituyen el texto que son: el discurso escrito como obra, la dialéctica entre palabra y escritura; el mundo del texto y la apropiación. La presente investigación se centrará principalmente en el primero y en el tercero.

21 Cf. Paul Ricœur, op. cit., pp.120 - 123.

22 Cf. Paul Ricœur, Temps et Récit I, Paris, Seuil, 1991 (Col. Points Essais, no. 227), pp. 93-162. El concepto de mundo del texto, se funda a su vez en los conceptos de mythos y mimesis, que en el presente artículo no se estudiarán pues desbordarían la investigación. Sin embargo es importante mencionar que en los conceptos de Mimesis I, II y III, se muestra como la imaginación recrea y transforma la realidad.

23 Cf. Paul Ricœur, Du texte a l'action. Essais d'herméneutique II, pp. 125-128.

24 Cf. Hans-Georg Gadamer, Verdad y Método II, $2^{\text {a }}$ ed., Salamanca, Sígueme, 1994 (Col. Hermeneia), p. 329. 
es el carácter denotativo de la significación ideal, es decir, su intencionalidad dirigida al mundo, su pretensión de alcanzar la realidad. Por último, los conceptos de disposición afectiva (Befinlichkeit) y comprensión (Verstehen), vienen a clarificar cual es la manera de referirse a la realidad. Por el temple de ánimo (Befinlichkeit), el Dasein está afectivamente abierto al mundo. El comprender por su parte, revela que el Dasein se encuentra constitutivamente en apertura a la realidad como un ser de posibilidades. ${ }^{25}$ Estos existenciarios muestran que para Ricœur, el mundo del texto revela una manera originaria de ser y estar en el mundo que es anterior a una relación cognoscitiva de sujeto-objeto, o a una relación meramente instrumental con los objetos. Es aquí donde se expresa con claridad la función de la imaginación. De la misma manera que en la metáfora la imaginación, a través del "ver como", suspende el sentido ordinario para abrirse a una significación de segundo grado, de igual forma, el mundo del texto, especialmente en la obras literarias y poéticas, lleva a cabo una epojé sobre la realidad ordinaria para luego revelar las posibilidades más propias del mundo y del ser humano. A este respecto Ricœur sostiene:

[...] las nuevas posibilidades de ser-en-el-mundo son abiertas en la realidad cotidiana, ficción y poesía se dirigen al ser, no más bajo la modalidad del ser-dado, sino bajo la modalidad del poder-ser. Por eso mismo la realidad cotidiana es metamorfoseada a favor de lo que podría llamarse las variaciones imaginativas que la literatura opera sobre lo real. ${ }^{26}$

El mundo del texto como horizonte de sentido muestra una realidad transformada que interpela al lector. El mundo del texto se dirige al mundo del lector y en esta interacción, el lector hace suyo el contenido de la obra alcanzado, a la vez una comprensión más enriquecedora de sí mismo. Con la apropiación del sentido del texto la intencionalidad del discurso escrito se completa, pues siempre el discurso es algo que está dirigido a alguien. La apropiación es una acción eminentemente subjetiva, pero no por ello arbitraria. Antes se realiza un proceso objetivo de explicación, ${ }^{27}$ después se despliega la potencialidad semántica de la obra a través de la noción del mundo del texto. Por último en la comprensión de sí, el sujeto no proyecta sus propios prejuicios (en sentido negativo) sobre el texto, sino al contrario se deja interpelar por "la cosa del texto" ${ }^{28}$ Esta dialéctica entre explicación objetiva y compren-

25 Cf. Martin Heidegger, Ser y Tiempo, Chile, Ed. Sudamericana, 1997, p. 158-164, 172-177. Parágrafos 29, 31 .

${ }^{26}$ Paul Ricœur, Du texte a l'action. Essais d'herméneutique II, p. 128.

${ }^{27}$ Cf. Paul Ricœur, Teoría de la interpretación: discurso y excedente de sentido, México, Universidad Iberoamericana, Siglo XXI, 1995, pp. 83 - 100. En este texto Ricœur expone en que consiste el momento metodológico de la explicación así como su relación dialéctica con la comprensión.

${ }^{28}$ Una conciencia hermenéuticamente formada se acerca al texto con una precomprensión previa, con unos prejuicios que son la condición de posibilidad de la inteligencia del texto. 
sión subjetiva es otra manera como Ricœur entiende la hermenéutica. ${ }^{29}$ Ahora bien, así como en la noción de mundo del texto la realidad es transformada al poner entre paréntesis la realidad ordinaria, en el sujeto, las consecuencias son semejantes al apropiarse del horizonte de sentido. Ricœur lo expresa de la siguiente manera:

[...] si la ficción es una dimensión fundamental de la referencia del texto, ella no es menos una dimensión fundamental de la subjetividad del lector... La lectura me introduce en las variaciones imaginativas del ego. La metamorfosis del mundo, según el juego, es también la metamorfosis lúdica del ego. ${ }^{30}$

\section{La imaginación social y cultural ${ }^{31}$}

Ricœur en su texto La imaginación en el discurso y en la acción ${ }^{32}$ muestra que la transición de una reflexión hermenéutica centrada en el texto, a una reflexión abierta a la comprensión de lo social puede hacerse a través de la imaginación en sus diferentes concreciones: como mimesis que redescribe las acciones humanas, como posibilidad de anticipación que anima las motivaciones y los proyectos, como percepción analógica de los otros, hasta llegar a la imaginación social. ${ }^{33}$

Ricœur considera que la imaginación social está constituida por una tensión dinámica entre ideología y utopía, así como por las contradicciones que hay al interior de cada una de ellas. Además, la ideología y la utopía se presentan como fenómenos ambiguos ya que en ambos se pueden encontrar funciones destructivas o constructivas. A continuación se expondrán algunos de sus rasgos fundamentales, para después comprender el dinamismo del imaginario social.

Para Ricœur, la primera función que caracteriza a la ideología es la de ser un proceso de inversión o distorsión de la realidad. Esta noción la toma de Marx, quien la desarrolla en sus escritos de juventud, de manera especial en la Crítica de la filosofia del derecho de Hegel, los Manuscritos de 1884 y La ideología alemana. Marx sostiene que lo determinante de la realidad es

Estos prejuicios son completamente distintos, de los que se hacen referencia en el presente párrafo.

29 Cf. Paul Ricœur, Du texte a l'action. Essais d'herméneutique II, pp. 184-185.

30 Ibidem, p. 131.

31 Cf. Paul Ricœur, Ideología y utopía, Barcelona, Gedisa, 2001, p. 60. Aunque Ricœur utiliza indistintamente los términos de imaginario social o cultural, cada uno tiene una significación específica. Lo social se refiere a los roles que las instituciones asignan o determinan a los individuos, mientras que lo cultural se refiere a las producciones de obras de la vida intelectual y a la creación de ideas.

32 Cf. Paul Ricœur, Du texte a l'action. Essais d'herméneutique II, pp. 237-262.

33 Cf. Marie-France Begué, op.cit., pp. 65-100. La autora profundiza las diversas maneras como la imaginación sirve de hilo conductor para pasar del texto a la dimensión social del ser humano. 
la praxis, ${ }^{34}$ es decir, las condiciones materiales de vida concreta y efectiva a partir de las cuales se relacionan los seres humanos en la sociedad. La ideología, por su parte, es el conjunto de ideas que se presentan como fundamento de la praxis, distorsionando en consecuencia la realidad. Para Marx, el ejemplo paradigmático de ideología es la religión, ya que ella es la proyección de las cualidades humanas en seres ficticios a los cuales después el sujeto se somete. Por eso no duda en afirmar que: "La crítica de la religión es la condición de toda crítica" ${ }^{35}$

La segunda función de la ideología toca un punto neurálgico de la sociedad: la legitimidad de la autoridad, la cual que se ejerce sobre los gobernados. Precisamente es Max Weber, a juicio de Ricœur, quien desarrolla con más profundidad esta segunda función. Según Weber cuando en un grupo social aparece la diferenciación entre los que poseen el poder del resto del grupo, es necesaria la ideología. La ideología llena el espacio que se abre entre el deseo de legitimación del poder por parte del grupo dominante y la creencia en dicha legitimación por el resto de la sociedad. Además, la tensión que se genera entre la legitimidad de la autoridad y la creencia de los ciudadanos en dicha legitimidad, nunca es proporcional, debido a que la exigencia de la autoridad siempre es mayor, que la creencia en ella, por parte de los ciudadanos. Llegados a este punto se pueden plantear dos cuestiones. La primera relacionada con la legitimidad del poder ¿Qué otra función de la ideología se puede obtener de la relación asimétrica entre legitimidad y creencia, que evite la fractura o explosión del grupo social? La segunda cuestión tiene que ver con la primera función de la ideología y es la siguiente. Si la función de la ideología es la distorsión e inversión de la realidad ¿quiere decir que hay una función más fundamental, anterior a la inversión, para que luego se presente como distorsión? Al respecto Ricœur contesta:

Si la realidad social no tuviera ya una dimensión ideológica y, por consecuencia, si la ideología en un sentido menos polémico y menos negativo, no fuera ya constitutiva de la existencia social sino pura distorsión o disimulación, entonces el proceso de distorsión no podría ponerse en marcha...Es solamente porque la estructura de la vida social de los hombres es simbólica que ella es susceptible de distorsiones. ${ }^{36}$

34 Cf. Étienne Balibar et al., « Praxis », en Barbara Cassin, Vocabulaire Européen des philosophies, Francia, Seuil-Le Robert, 2004, pp. 988-1202. El término praxis posee además dos connotaciones muy importantes por una parte expresa la relación dialéctica entre el hombre y la naturaleza. La praxis en este sentido es la humanización de la naturaleza y la naturalización del hombre. Por otra parte adquiere la categoría de una acción liberadora de la realidad a través de las fuerzas productivas del trabajo.

35 Paul Ricœur, L'idéologie et l'utopie, Paris, Seuil, 1997 (Col. Points Essais, no. 538), p. 43. 
Lo anterior nos conduce a la tercera función, que consiste en la capacidad que tiene la ideología para dar cohesión e identidad al grupo social. Ricœur desarrolla este rasgo de la ideología a partir de los aportes de la antropología cultural de Cliffort Geertz. La función más profunda de la ideología es la de la integración. El hecho de que una sociedad pueda mantenerse cohesionada es gracias a la ideología. En este sentido la ideología puede entenderse como el conjunto de redes simbólicas a partir de las cuales una colectividad se representa a sí misma y toma conciencia de sí. Además la ideología no es sólo el espejo en donde la sociedad o el grupo social se representa, también es el conjunto de mediaciones simbólicas que constituyen cualquier acción social. Por ello Ricœur sostiene: "Todo grupo... adquiere una consistencia y una permanencia gracias a la imagen estable y durable que se da él mismo. Esta imagen estable y durable expresa el nivel más profundo del fenómeno ideológico". ${ }^{37}$ Uno de los ejemplos más claros en donde se puede a preciar la función de integración de la ideología es la celebración de un hecho histórico a partir del cual un grupo social se reconoce a sí mismo como autónomo e independiente. Este hecho se constituye en acontecimiento fundante de una sociedad.

A partir de la exposición de los rasgos esenciales de la ideología, en seguida se expondrán las funciones esenciales de la utopía, las cuales, como se podrá apreciar, tienen una relación estrecha con la ideología.

La función primera que aparece en la utopía, partiendo de su significación literal "ningún lugar", "ninguna parte", es la de proponer otras maneras de concebir las relaciones sociales en sus diferentes niveles: económico, político, religioso, familiar, de consumo. La utopía al mostrar una nueva manera de ser y de vivir la sociedad en su conjunto, abre en el presente posibilidades futuras, por eso "La utopía aparece así, en su nudo primitivo, como la contrapartida exacta... de [la] ideología en tanto que función de la integración social. La utopía, por el contrario, es la función de la subversión social". ${ }^{38}$

La segunda función se dirige al núcleo de esta subversión social: la legitimación de la autoridad. Nuevamente la utopía como elemento crítico cuestiona las maneras concretas de ejercer la autoridad en los diferentes ámbitos de la vida familiar, social, política, económica y de consumo. Los análisis que Ricœur realiza sobre las utopías de Saint-Simon y Fourier lo confirman de manera clara. Para el primero, la dirección de la sociedad recae en los artistas, los sabios y los industriales, quienes coordinados entre sí debían atender las necesidades de la mayoría de la sociedad, es decir, la de los pobres. El segundo considera que el ejercicio del poder de una sociedad debe enraizarse y estar en armonía con las pasiones del ser humano. La función de la autoridad por un 
parte, debería consistir sólo en la administración de los bienes y por otra parte en el despliegue y desarrollo de las pasiones de los individuos. ${ }^{39}$

El tercer rasgo de la utopía, que se relaciona con el primero que se expuso de la ideología, consiste en llevar hasta el extremo su significación etimológica, "ninguna parte", ya que significa la renuncia a transformar las condiciones actuales de una sociedad, asumiendo una actitud evasiva y esquizofrénica frente a la realidad. En esta función, la utopía al no proponer medios concretos para transformar la realidad, se proyecta hacia un pasado mítico y consolador.

La exposición de las funciones de ambos fenómenos nos permite observar las contradicciones al interior de cada uno de ellos, así como la diversidad de relaciones que se pueden dar entre ambos. La ideología es tanto un fenómeno de integración de un grupo social, como un proceso de distorsión e inversión de lo real. La utopía por su parte es un elemento crítico y subversivo frente a un status quo, así como una evasión. Las relaciones entre la ideología y utopía se presentan ambiguas y en tensión. Así por ejemplo, mientras la ideología es un elemento coercitivo, la utopía puede ser un factor liberador. Por otra parte, si la utopía es una fuga de la realidad presente, la ideología se caracteriza por tener una función de integración y de consolidación de la sociedad.

Pasando a la función de la imaginación en ambos fenómenos se puede reflexionar lo siguiente.

De manera general se puede decir que la imaginación está presente en ambos fenómenos debido a que el imaginario social y cultural consiste en las mediaciones simbólicas por las cuales una sociedad se constituye, se expresa y actúa, De forma más específica se puede precisar lo siguiente. En relación con la ideología, Ricœur siguiendo a Clifford Geertz, sostiene que si se desea comprender la función de integración que la ideología ejerce en la sociedad, es preciso conocer el rol que desempeña la retórica en la construcción del discurso público. La comprensión de la retórica requiere el conocimiento de las figuras de estilo - metáforas, analogías, hipérboles, juego de palabras- por las cuales se articula el discurso público. De esta forma se puede conocer el alcance y la fuerza de los símbolos sociales, y por ende el de la imaginación, a partir de los cuales se articula la ideología. Respecto a la utopía, Ricœur, al hablar de su carácter subversivo y creativo menciona el lugar básico que ocupa la imaginación:

Si yo debiera relacionar esta estructura de la utopía a la filosofía de la imaginación, yo diría que ella se aproxima a las variaciones imaginarias alrededor de una esencia que propone Husserl... El género de neutralización que constituye la imaginación como ficción esta a la obra en la utopía. ${ }^{40}$ 
La imaginación en la utopía se expresa como la capacidad de hacer epojé sobre la realidad presente proponiendo variantes nuevas a las condiciones como una sociedad está organizada. La imaginación también se puede manifestar de forma enajenante al fugarse de la realidad misma.

\section{Reflexión final}

Con base en el recorrido realizado por la metáfora, el mundo del texto y el imaginario social, en este último apartado se tratarán tres aspectos. En primer lugar se explicitarán los elementos a partir de los cuales se articula el concepto de imaginación. Después se reflexionará sobre su trascendencia en el conjunto del pensamiento de Ricœur. Por último se sugerirá, brevemente, la aplicación de los conceptos de ideología y utopía, como instrumentos teóricos, para analizar la realidad política y social.

El análisis precedente nos ha permitido identificar algunos elementos básicos que conforman la imaginación en la fenomenología hermenéutica de Paul Ricœur. El primero es el esquematismo kantiano por el que la imaginación se considera como el método que genera y que posibilita la creación. Esta imaginación productiva se completa a través de dos conceptos de origen husserliano: la epojé y las variaciones imaginativas. La epojé pone entre paréntesis la realidad ordinaria tanto en la metáfora, como en el mundo del texto y la utopía. Gracias a esta puesta entre paréntesis, la imaginación realiza una variación o modificación neutralizante que permite introducir lo posible en la realidad para enriquecerla con múltiples perspectivas. ${ }^{41}$ El estudio de la metáfora, del mundo del texto y del imaginario social y cultural nos muestra otras características esenciales de la imaginación. En la metáfora, la imaginación, se nos presenta como superadora del lenguaje ordinario. En el mundo del texto, además de redescribir la realidad presente, su acción se extiende al mundo del lector en donde ejerce una transformación lúdica. Por último, la imaginación social y cultural nos revela otro aspecto: su dimensión consti-tuyente. Es importante notar que estos rasgos de la imaginación, se conservan por efecto de agregación al pasar de la metáfora al mundo del texto, y de éste, a la ideología y a la utopía en su sentido positivo. Ahora bien, la imaginación en su dimensión social y cultural, también manifiesta con claridad sus aspectos patológicos y destructivos. Esta dimensión negativa quedaba oculta o latente en el estudio de la metáfora y el mundo del texto, ya que en estas nociones el acento recae principalmente en la capacidad de mostrar la realidad de manera originaria, así como en la de desplegar los posibles más propios del ser humano.

${ }^{41}$ Cf. María Manuela Saraiva, L'imagination selon Husserl, La Haya, Martinus Nijhoff, 1970, pp. 175-203. La autora realiza un estudio sistemático sobre el concepto de la imaginación en Husserl. En el capitulo IV expone el concepto de neutralización al que Ricœur se refiere en la cita no. 39 . 
Pasando al rol que la imaginación desempeña en el conjunto de la fenomenología hermenéutica del filósofo francés, se puede reflexionar lo siguiente. Ricœur en el estudio VIII, 4 de La Metáphore vive aborda el problema de la interacción del discurso filosófico y el discurso literario. ${ }^{42}$ Ahí sostiene que el trabajo del concepto es propio de la intellectio y la creación de la metáfora es propia de la imaginatio. Al hablar de la función que realiza la imaginación en esta interacción de discursos sostiene:

[...] ahí donde el entendimiento fracasa, la imaginación tiene todavía el poder de 'presentar' (Darstellung) la Idea. Es esta 'presentación'de la Idea por la imaginación que obliga al pensamiento a pensar mas. La imaginación no es otra cosa que esta demanda dirigida al pensamiento conceptual. ${ }^{43}$

La afirmación de que "la imaginación obliga al pensamiento a pensar más", se relaciona con otra expresión que Ricœur utiliza en la conclusión de La symbolique du mal: "el símbolo da que pensar". Ambas expresiones revelan aspectos interesantes de su propuesta. Por una parte se pone de manifiesto la interacción del discurso poético y filosófico, lo cual plantea un problema, debido a que el lenguaje poético, ya sea simbólico o metafórico, se dirige a lo concreto y vital, mientras que el discurso filosófico tiende a lo universal y conceptual ¿cómo salvar la diferencia entre lo concreto y lo universal, lo vital y lo conceptual? Precisamente, para Ricœur la imaginación, en el sentido kantiano, es la instancia que salva la diferencia y que hace posible la interacción de ambos discursos, porque ella, como condición de posibilidad tiene la capacidad de realizar la sintesis de lo diverso. Por ello, la imaginación en su sentido productivo puede presentar la Idea al entendimiento para animarlo en su tarea de pensar más. Lo anterior, muestra una característica fundamental de la hermenéutica filosófica de Ricœur: su función mediadora, entre la multiplicidad de significados del lenguaje poético (simbólico, metafórico y literario), y la univocidad y claridad propia del pensamiento especulativo. Esta capacidad de mediación implica que la dinámica de la reflexión ha de estar animada por una dialéctica entre el intellectio y la imaginatio, lo cual nos lleva a afirmar que la imaginación es un elemento esencial de la racionalidad. Con base en lo anterior, se puede sostener que la fenomenología hermenéutica de Paul Ricœur se opone a aquella tradición filosófica que planteando una dicotomía a nivel ontológico y epistemológico, pone a la imaginación del lado del no ser y de la falsedad. ${ }^{44}$ La fenomenología hermenéutica del pensador francés

Cf. Fernanda Henriques, Filosofia e Literatura. Um Percurso Hermenêutico com Paul Riccur, Porto, Ed. Afrontamento, 2005. Fernanda Henriques desarrolla como tesis principal que el discurso poético, en su sentido más amplio, revela un rasgo esencial de la propuesta de Ricœur, que consiste en la presencia de la alteridad en el discurso filosófico.

44 Cf. Richard Kearney, Poétique du possible, Paris, Beauchesne, 1984, pp. 11-42. Richard Kearney plantea la necesidad de superar el dualismo ontológico y epistemológico que va 
exige una reformulación de la racionalidad que supere un dualismo ontológico de la subjetividad. ${ }^{45}$

La dialéctica entre intellectio e imaginatio propia de la racionalidad hermenéutica, no sólo se caracteriza por su apertura a las significaciones y referencias del lenguaje poético, en sus diversas expresiones, sino también por una actitud crítica frente a ellas. Tal es la posición que asume Ricœur en La symbolique du mal, al llevar a cabo un proceso de desmitologización en los símbolos de segundo, de manera especial, en el mito adámico. También es patente en la obra De l'interpretation. Essai sur Freud, al considerar el psicoanálisis, como un ejemplo de una hermenéutica de la sospecha, que esclarece el significado del simbolismo onírico. Por último, se pone de manifiesto al tratar el problema de la comprensión de sí, como elemento propio de la hermenéutica, pues sostiene la necesidad de asumir la crítica de las ideologías tal como lo propone la Escuela de Frankfurt, en especial los planteamientos de Habermas. ${ }^{46}$ Así, una apertura a los discursos que muestran maneras nuevas de estar en el mundo, se debe completar con una crítica tanto a los procesos de inversión de la realidad, de legitimación de la autoridad opresora, de masificación y formación de un pensamiento único, propias de las ideologías, como a las propuestas enajenantes de los discursos utópicos que no hacen sino reforzar la dominación ideológica.

El análisis realizado sobre el imaginario social nos permite sugerir algunas preguntas sobre casos concretos de la realidad política y social. Un ejemplo de ello sería el proceso electoral que se vivió en México para elegir presidente de la República. Al respecto se puede formular la siguiente cuestión: ¿el proceso electoral que se realizó el pasado 2 de julio de 2006, tuvo la transparencia necesaria que legitime la toma del poder por el candidato del Partido de Acción Nacional (PAN), frente al candidato del Partido de la Revolución Democrática (PRD) y los partidos que lo apoyaron? Esta cuestión, como se puede observar con claridad, se refiere a una de las funciones básicas de la ideología: la legitimación del grupo en el poder y la creencia de la sociedad civil en el proceso realizado. Por su parte, el candidato del PRD, frente a la resolución del Tribunal Federal Electoral que dio el triunfo al candidato del PAN, a pesar de "ciertas irregularidades," hizo un llamado para realizar una asamblea nacional el día 16 de septiembre, fecha en el que se festeja la independencia nacional, para organizar un frente de resistencia civil en todo el país. ¿Cómo articulará en su discurso político los símbolos que constituyen

de Platón a Sartre, y para ello propone la noción fenomenológico-hermenéutica de figuración creativa. Esta noción permite comprender que todas las dimensiones de la existencia humana poseen una intencionalidad posible.

45 Cf. Paul Ricœur, op. cit., pp. 202-203. Esta es la conclusión a la que llega en su estudio "explicar y comprender", al proponer la superación de un dualismo epistemológico que se prolongue en uno de carácter ontológico. 
el imaginario social, que le permita mostrarse como defensor de la democracia y no como agente de disolución de la misma?

Estas breves cuestiones tienen la finalidad de mostrar que la reflexión de la fenomenología hermenéutica de Paul Ricœur sobre el imaginario social puede proporcionar instrumentos de análisis, que junto con aportes de otras disciplinas, realice una comprensión crítica de la realidad política y social. Pues ¿Cómo se podría cambiar o transformar las situaciones sociales y políticas presentes, si antes no se intenta comprenderlas?

\section{RESUMO}

O presente estudo trata da teoria da imaginação em Paul Ricœur. Tema recorrente da obra ricœuriana, a imaginação articula-se com um conjunto de outras temáticas do autor, nomeadamente, a da metáfora, a da identidade narrativa, a da simbólica do mal.

$\mathrm{Na}$ impossibilidade de um tratamento global das questões, focar-se-ão apenas três temas: o da metáfora, o do mundo do texto e o do imaginário social e cultural. $\mathrm{O}$ percurso por esta trilogia permitirá encontrar algumas raízes fundamentais do pensamento e da obra de Ricœur, como é o caso do esquematismo kantiano

Palavras-Chave: imaginação, metáfora, texto, fenomenologia, interpretação.

\section{RÉSUMÉ}

Cette étude porte sur la théorie de l'imagination chez Paul Ricœur. Thème récurent dans l'œuvre ricœurienne, l'imagination s'articule sur un ensemble d'autres thématiques propres à l'auteur, notamment celle de la métaphore, de l'identité narrative et de la symbolique du mal. Face à l'impossibilité de traiter la totalité de ces questions, nous nous concentrerons sur trois thèmes : celui de la métaphore, celui du monde du texte et enfin l'imaginaire social et culturel. Le parcours au travers de cette trilogie nous permettra de trouver certaines racines fondamentales de la pensée et de l'œuvre de Ricœur, comme c'est le cas du schématisme kantien.

Mots Clés: imagination, métaphore, texte, phénoménologie, interprétation. 